\title{
O "CORPO" COMO TEMA DA PRODUÇÃO DO CONHECIMENTO NA REVISTA BRASILEIRA DE CIÊNCIAS DO ESPORTE - RBCE (1979-2012)
}

DOI: $105902 / 0102830822566$

Data de submissão: 08-06-2016 Data de Aceite:21-10-2016

Fabio Zoboli

Universidade Federal de Sergipe zobolito@gmail.com

Renato Izidoro da Silva Universidade Federal de Sergipe izidoro.renato@gmail.com

Elder Silva Correia Universidade Federal do Espírito Santo eldercorreia21@gmail.com

João Filipe dos Santos Universidade Federal de Sergipe joao.filipe.dos.stos@gmail.com

Vinícius dos Santos Souza Universidade Federal de Sergipe vinicius.santos.2607@gmail.com

Tiago de Brito Ferreira Santos Universidade Federal de Sergipe tiagopaulista10@gmail.com

Resumo: Bibliometria da produção do conhecimento da temática "corpo" na Revista Brasileira de Ciências do Esporte 1979-2012. O estudo é do tipo bibliométrico com abordagem quali-quantitativa de caráter descritivo. Os termos de busca foram: "corpo", "corporeidade", "corporal" e "corporalidade", todos aplicados segundo os filtros "título" e "resumo". Como resultados foram encontrados 121 trabalhos a partir dos quais foram construídas escalas de medidas para enquadrar o quantitativo das produções científicas. Os trabalhos analisados foram agrupados em seis categorias: "fundamentos e propostas pedagógicas", "Educação Física e epistemologia", "corpo e identidade cultural", "corpo e estética", "motivação e exercício" e "outros".

Palavras-chave: Bibliometria; Corpo; Revista Brasileira de Ciências do Esporte; Educação Física. 


\section{INTRODUÇÃO}

Este texto é resultado de uma pesquisa bibliométrica que é parte de um projeto mais amplo envolvendo três Universidades Federais (Sergipe/UFS, Espírito Santo/UFES e Santa Catarina/UFSC) cujo objetivo foi diagnosticar as produções em nove periódicos da Educação Física (EF) brasileira que tenha relação com a temática "corpo" buscando oferecer um mapeamento do conhecimento produzido sobre o tema nas últimas décadas. Desta forma o presente artigo apresenta um fragmento de resultados desta pesquisa maior, na medida em que tem seu foco voltado para a exposição dos resultados referentes à Revista Brasileira de Ciências do Esporte - RBCE. Nosso recorte temporal inicia em 1979 (ano da primeira edição da RBCE) e vai até as edições publicadas no ano de 2012 (pois nossa pesquisa teve iniciou em janeiro de 2013).

O corpo é central não só na esfera da Educação Física, mas no contexto das mais variadas ciências e campos epistemológicos. No cenário da Educação Física o corpo tem se apresentado como objeto de estudo a partir de várias problemáticas. "A problemática do corpo pode apresentar indicadores para a configuração epistemológica da Educação Física, haja vista a existência de um número significativo de pesquisas que enfocam questões relativas ao corpo" (NÓBREGA, 2006, p.60). Desta forma entendemos o corpo neste escrito a partir de sua extensão representacional no campo do cultural, ou seja, o corpo é aqui apresentado como vetor semântico pelo qual a evidência da relação com o mundo é construída. Para Bártolo (2007), onde se encontra um corpo dever-se-á encontrar também uma rede de relações instrumentais, uma série em funcionamento, de operadores epistêmicos, uma lógica de produção de sentidos, de um determinado sentido legitimador da rede de relações, do funcionamento dos operadores, do próprio procedimento das lógicas produtivas. O corpo enquanto objeto de pesquisa sob o viés da Educação Física é algo a ser significado, neste sentido Le Breton (2009 p.24) afirma que "qualquer questionamento sobre corpo requer antes a construção de seu objeto, a elucidação daquilo que subentende".

E continua “O ‘corpo' é uma linha de pesquisa e não uma realidade em si” (LE BRETON, p.33, 2009).

No que diz respeito a práticas bibliométricas no campo, podemos identificar essa 
possibilidade de mapeamentos sobre publicações com temáticas pré-determinadas na Educação Física a partir da década de 1980. Neste período fazer um levantamento do que se produzia no campo já se apresentava como uma necessidade para se pensar ou orientar seu próprio desenvolvimento oferecendo aos sujeitos que se aproximavam do mesmo ou nele adentravam uma probabilidade de direcionar ou contextualizar suas produções (BRACHT et al, 2011).

O estímulo a este tipo de levantamento de dados se pauta muito na possibilidade de gerar um mecanismo de consulta a novos pesquisadores sobre as lacunas, tendências ou prioridades no que tange as produções científicas nas revistas/periódicos. Noronha e Ferreira (2000) em seus estudos apontam como relatórios de estado da arte podem ser importantes no que tange a inovações e métodos sobre tópicos específicos ou subtemas dentro do âmbito da produção científica de determinada área/campo. Assim, as bibliometrias, mapeando as repetições, as saturações, a falta de inovação, a estagnação diante de problemas teóricos, metodológicos e sociais, contribuem para orientar mudanças nas políticas editoriais de revistas e de livros, as seleções de projetos de mestrado e de doutorado no âmbito dos programas de pós-graduação, bem como a publicação de editais - públicos ou privados - de fomento à pesquisa científica, tudo no sentido de equalizar a relevância das propostas.

Com o objetivo de diagnosticar as produções da Revista Brasileira de Ciências do Esporte (RBCE) que tenha relação com a temática "corpo" buscando oferecer um mapeamento do conhecimento produzido sobre o tema no período de 1979 até 2012, o texto foi estruturado a partir de duas partes. A primeira se dispõe a dissertar sobre alguns conceitos teóricometodológicos gerais da bibliometria; caracterizar a pesquisa e o tipo de análise empregada para a constituição do presente estudo e descrever os procedimentos específicos adotados no processamento dos dados coletados. A segunda parte do artigo apresenta os resultados obtidos de forma descritiva sob o ponto de vista quali-quantitativo. 


\section{METODOLOGIA}

A presente pesquisa consiste numa bibliometria composta por procedimentos de quantificação baseados em categorias temáticas que orientam a produção e a gestão do conhecimento científico. Sobre o termo bibliometria, Bufrem e Prates (2005, p. 11) destacam que se trata de uma "[...] junção do grego biblion, que significa livro, com o latim metricus e o grego metrikos, que significam mensuração, refere-se a um conceito usualmente definido como um processo de medida relacionada ao livro ou ao documento".

A presente bibliometria mapeia e analisa o tema corpo na RBCE sob o ponto de vista quali-quantitativo (ou misto) descritivo. Sob o viés quali-quantitativo vale mencionar que "[...] nem a primeira está isenta de quantificação nem a segunda prescinde de raciocínio lógico. São sim alternativas metodológicas para a pesquisa, e a denominação [...] não delimita [...] objetos qualitativos e quantitativos, nem [...] paradigmas científicos [...]" (PEREIRA, 2004, p. 25). Por esse caminho, Pereira (2004, p. 22) explica que a abordagem quantitativa não é possível quando o pesquisador não dispõe de conhecimento anterior do objeto pesquisado. Trata-se de considerar a classificação qualitativa dos objetos como atitude epistemológica ou gnosiológica primária do pensamento e de seus vínculos com as sensações. "É, então, a abordagem qualitativa que viabiliza, pelo menos, o primeiro reconhecimento do objeto e, eventualmente, instrumentaliza uma posterior abordagem alternativa" (PEREIRA, 2004, p. 25). Em outras palavras, se não há o conhecimento qualitativo como primário não é possível quantificar o desconhecido. O número só faz sentido quando enumera, ordena ou quantifica coisas que possuem nomes; sendo que tais nomes são dependentes das qualidades sensitivas ou utilitárias dos objetos.

Embora a bibliometria inclua técnicas estatísticas como parte de suas análises, a presente pesquisa assume um ponto de vista quantitativo, porém, não-estatístico. Isso se deve ao fato de termos limitado este trabalho à exposição dos procedimentos de coletas, organização e análise quantitativas - ou numéricas - de dados ou informações extraídas das publicações veiculadas na RBCE. Trata-se, portanto, de uma pesquisa quantitativa de levantamento descritivo de dados, que pode ser entendida como uma parte dos estudos estatísticos chamada de "Estatística Descritiva" (VIEIRA, 2010, p. 8); pois, encerramos o 
levantamento na etapa de apresentação de tabelas, quadros e gráficos responsáveis por sistematizar e expor organizadamente os dados coletados.

Em suma, não ponderamos os aspectos que poderiam tornar nossa amostra bibliográfica como representativa - generalizável - das dispersões, padrões, tendências, repetições e probabilidades sobre as abordagens teórico-metodológicas em torno do tema "corpo" nos demais periódicos. Nesse sentido, embora o estudo tenha gerado inevitavelmente escalas nominais (modas), ordinais (medianas) e intervalais, (médias) concernentes aos dados qualitativos, não realizamos análises das relações entre essas escalas de modo a interpretar as dispersões ou confluências em torno das medidas de tendência centrais (VIEIRA, 2010, p. 47).

Neste sentido, o presente artigo teve como objetivo mapear e analisar informações dos textos da RBCE que tinham como objeto de investigação a temática "corpo". Tal periódico foi escolhido a partir dos seguintes critérios: 1) periódico da área com maior ciclo de vida; 2) está ligado a uma importante instituição da área da Educação Física, que é o Colégio Brasileiro de Ciências do Esporte (CBCE); 3) os dois critérios acima levam a hipótese de que o referido periódico pode expressar as mudanças históricas e epistemológicas que o campo da Educação Física passou, sobretudo nas concepções de "corpo" - objeto específico do presente estudo; 4) o periódico figura atualmente como extrato "B1" no sistema webqualis (na área da Educação Física).

Desta forma, nosso percurso metodológico ocorreu em dois momentos, "coleta e organização dos dados" e "análise e interpretação quantitativa dos dados". Primeiramente (na coleta e organização dos dados), detectamos os artigos da RBCE que tratavam da temática "corpo", para tanto fizemos uma busca no site da revista, marcando as opções por título e resumo, a partir das seguintes palavras-chave: "corpo", "corporeidade", "corporalidade" e "corporal". Ou seja, nos interessou apenas os artigos que tivessem em seus títulos e/ ou resumos as palavras-chave citadas anteriormente. A partir disso fizemos uma lista no Microsoft Excel com todos esses artigos encontrados, que totalizou 172 artigos.

Para uma melhor delimitação dos textos que foram analisados, estabelecemos alguns critérios de corte: 1) artigos que tratavam o corpo pautado sob o viés das ciências biomédicas ou biodinâmicas e permaneceram apenas os textos que se encaixavam na subárea sociocultural/pedagógica. 2) textos de anais de eventos e congressos; 3) textos 
em forma de resumo; 4) resenhas de livros; 5) produções que traziam a palavra "corpo" em outros sentidos, como "corpo docente", "corpo do texto" e "corpo discente". Tratou-se assim de uma amostra não aleatória e não probabilística. Sendo, portanto, uma amostragem por conveniência.

Aplicados estes critérios foram excluídos do estudo 51 artigos e a nossa amostra ficou então composta por 121 artigos publicados no período entre 1986 a 2012.

Referente aos procedimentos de busca, um fator importante a destacar são duas diferentes formas digitais das publicações encontradas na revista RBCE. Concernente às versões exclusivamente impressas durante o período entre 1979 e 1999, cada exemplar foi digitalizado (via scanner) em suas integralidades, impossibilitando o acesso individual dos artigos das edições, salvo algumas exceções no período de 1996 a 1999 cujos artigos foram digitalizados individualmente. Após esse período os artigos passaram a ser publicados no site da revista digitalizados separadamente. Com isso, a coleta através das palavras-chave do período de 1979 a 1999 ocorreu com a leitura dos títulos e resumos de cada texto.

Com a amostra definida foi feita uma segunda tabelas no Microsoft Excel separando os textos por ano de publicação e sistematizando informações sobre os autores (quantidade, região, titulação), bem como sobre a temática geral do texto (resumo, título, mês e ano de publicação). Desta forma nos preocupamos em identificar as seguintes informações dos textos: Título; Resumo; Tema Central; Mês/Ano/Edição; Instituição; Região; Titulação dos Autores; Número de Autores. Além disso, também houve uma análise dos artigos no sentido de distribuí-los em categorias temáticas na tentativa de visualizar com quais temáticas as pesquisas relacionadas ao "corpo" foram tratadas.

\section{ANÁLISE E INTERPRETAÇÃO DOS DADOS}

Como mencionamos na metodologia, fizemos a busca em "títulos" e "resumos" pelas publicações por meio das seguintes palavras-chave: corpo, corporeidade, corporalidade e corporal. Neste sentido, o gráfico 1 mostra o quantitativo de publicações encontradas por cada palavra-chave: "corpo" 101 ocorrências; "corporal" com 91 publicações; corporeidade" e "corporalidade" com 14 e 13 respectivamente. Neste sentido, as 4 palavras-chave foram 
mencionadas 219 vezes. Vale ressaltar que tiveram publicações que continham mais de uma palavra-chave (em seus títulos ou resumos), estando assim o texto contabilizado mais de uma vez.

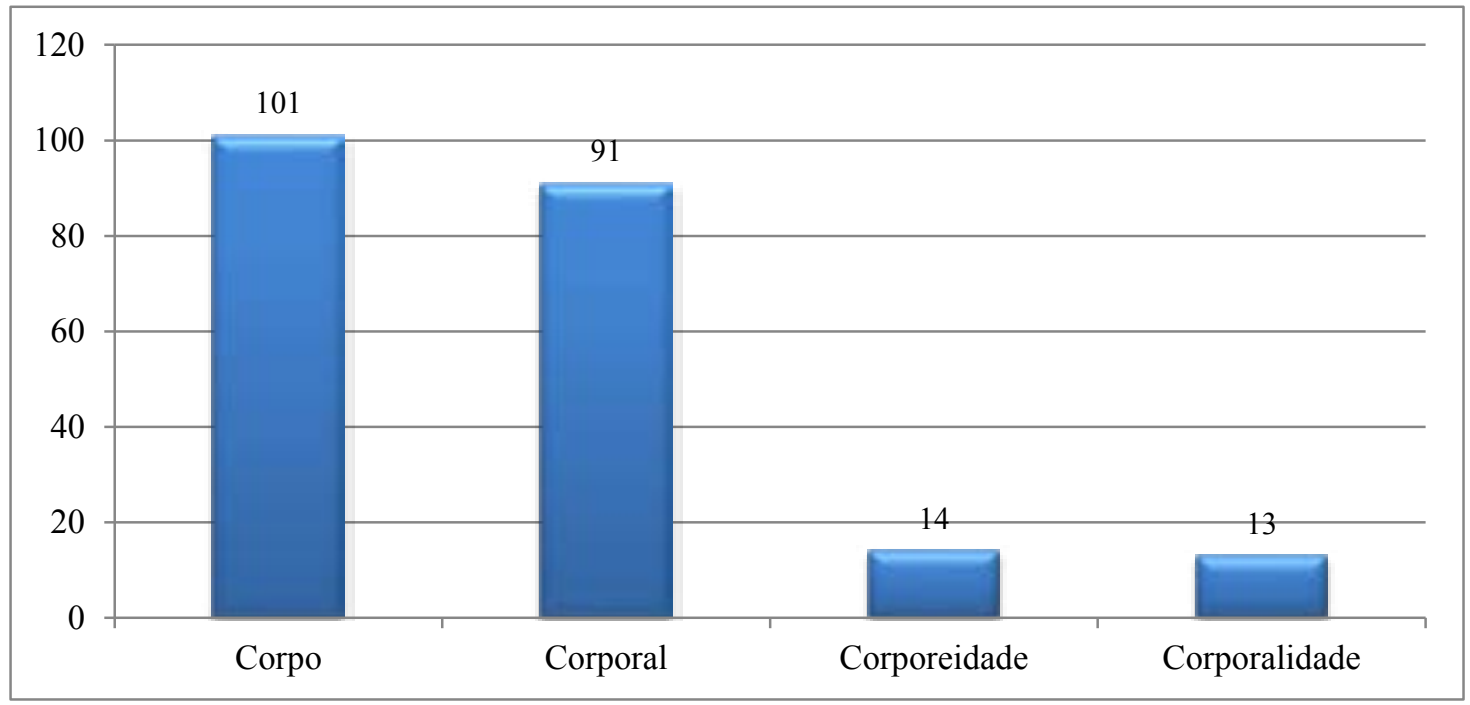

Gráfico 1 - Quantidade de publicações encontradas por palavras-chave

No gráfico 2, apresentamos os artigos separando-os por décadas. Os artigos que tratavam sobre temáticas relativas ao "corpo" foram encontrados no periódico já a partir da década de 1980. Visualizamos no gráfico abaixo que em sua primeira década (1980), o periódico publicou um total de 8 artigos, e já em sua segunda década (1990) foram publicados um total de 21 artigos, ou seja, 13 a mais do que a década de 1980. Na década de 2000 (incluindo mais dois anos, afinal nosso recorte temporal foi até 2012), fora encontrado um total de 92 artigos, ou seja, 71 a mais do que a década de 90, e 84 a mais do que a década de 80. Neste sentido, percebemos uma crescente de artigos publicados no decorrer das décadas, totalizando 121 artigos publicados. 


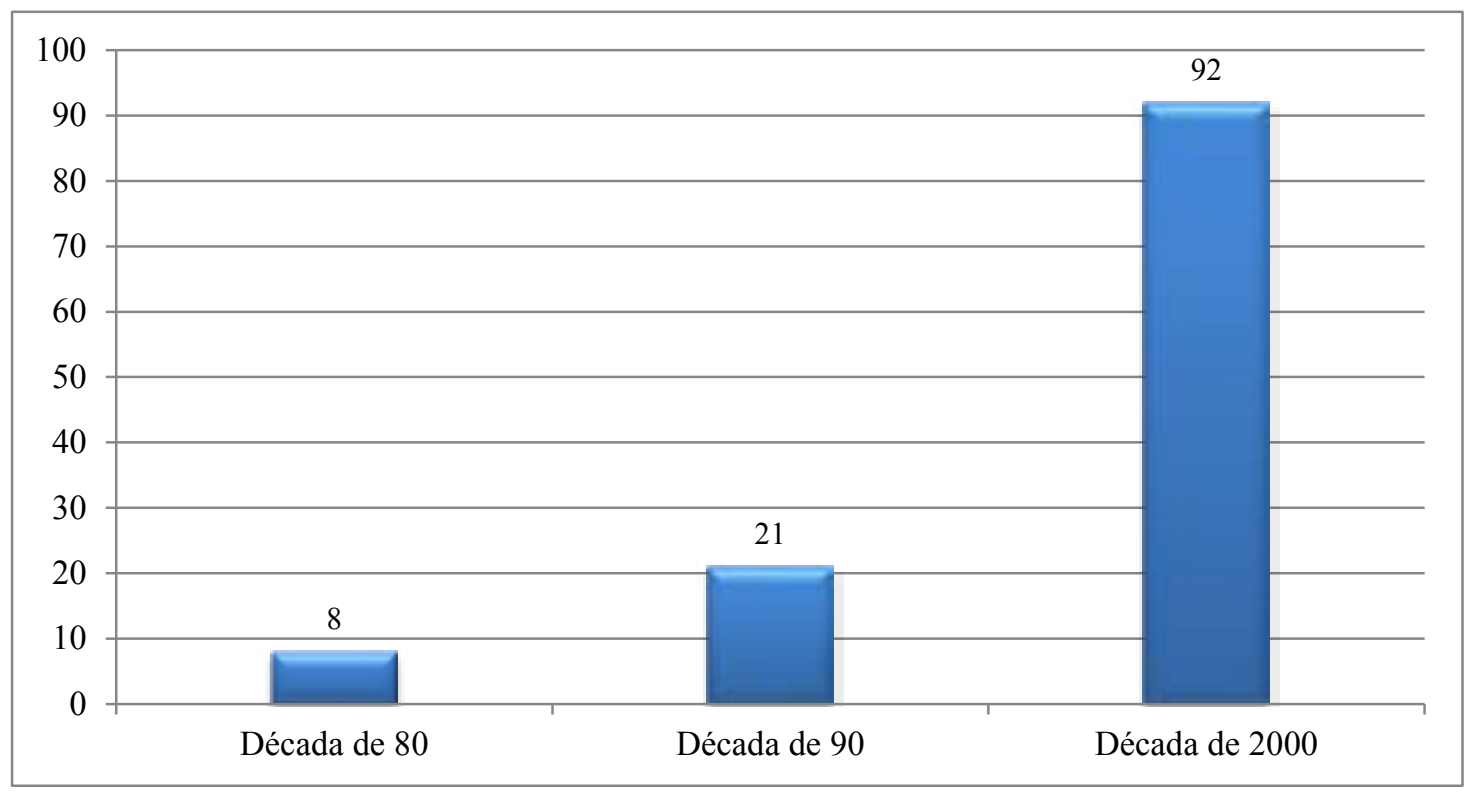

Gráfico 2 - Publicações por décadas

No gráfico 3, apresentamos o total de artigos separados por ano em que houve publicação relacionada ao tema. Podemos perceber que o primeiro ano que apresentou textos relativos a temática "corpo" foi o ano de 1986. É possível visualizar também que entre os anos de 1986 e 2004, não houve muita alteração entre a quantidade de artigos publicados, variando entre 3 e 7 publicações. Porém nos anos de 2005 e 2006, houve um aumento de 7, para 13 publicações, o que corresponde a quase o dobro de publicações em relação ao maior número de publicações por ano até 2004. Entre 2007 e 2012 o número de publicações por ano caiu, sendo que o ano que teve menos quantidade foi o de 2008 com 2 artigos, e os anos com maior número de publicações foram os anos de 2007, 2009 e 2011 com 7 publicações cada; isso mostra uma variação entre 2 a 7 artigos publicados após a queda de publicações detectada em 2007. Neste sentido, o que podemos observar é que entre 1986 a 2004 houve uma média de publicação que variou entre 3 e 7 artigos. Já os anos de 2005 e 2006 fugiram dessa média, depois a partir de 2007 voltou a ter novamente uma média. Cabe destacar também que nos anos 1987, 1995, 1998 e 1999, não houve nenhuma publicação de produção relacionada à temática. 


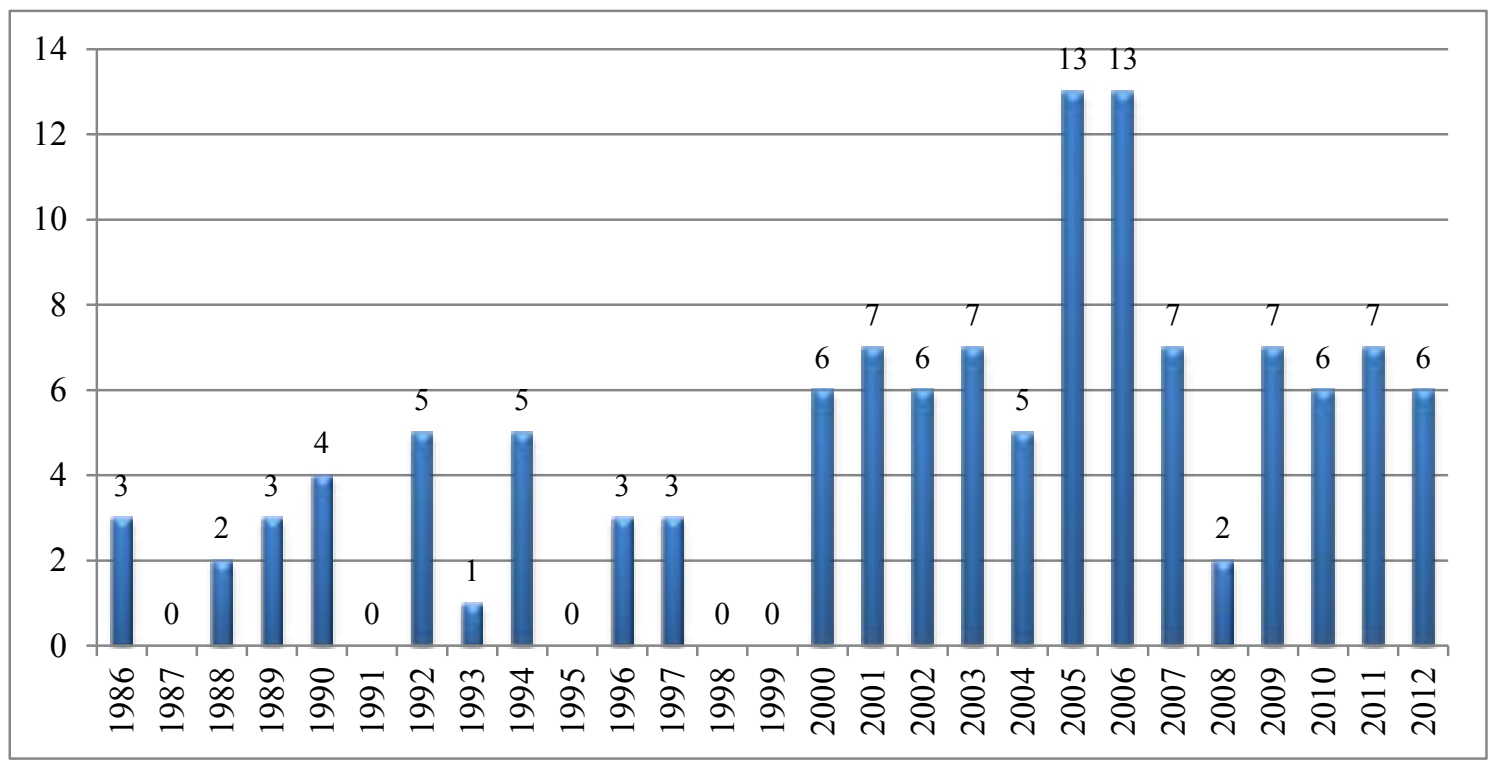

Gráfico 3 - Publicação por ano

No que diz respeito as instituições as quais os 121 textos estão ligados, no corpo destas produções identificamos 56 instituições, e um total de 136 ocorrências. Assim, como podemos visualizar no gráfico 4 , as instituições que mais apareceram foram a Universidade Federal de Santa Catarina - UFSC, com 21 aparições; logo depois aparece a UNICAMP - Universidade Estadual de Campinas com 17; em seguida aparece 1 universidade com 5 ocorrência; 5 instituições com 4 ocorrências; 9 universidades aparecendo 3 vezes; com 2 ocorrências foram encontradas 8 instituições e por fim, 30 universidades com 1 ocorrência cada.

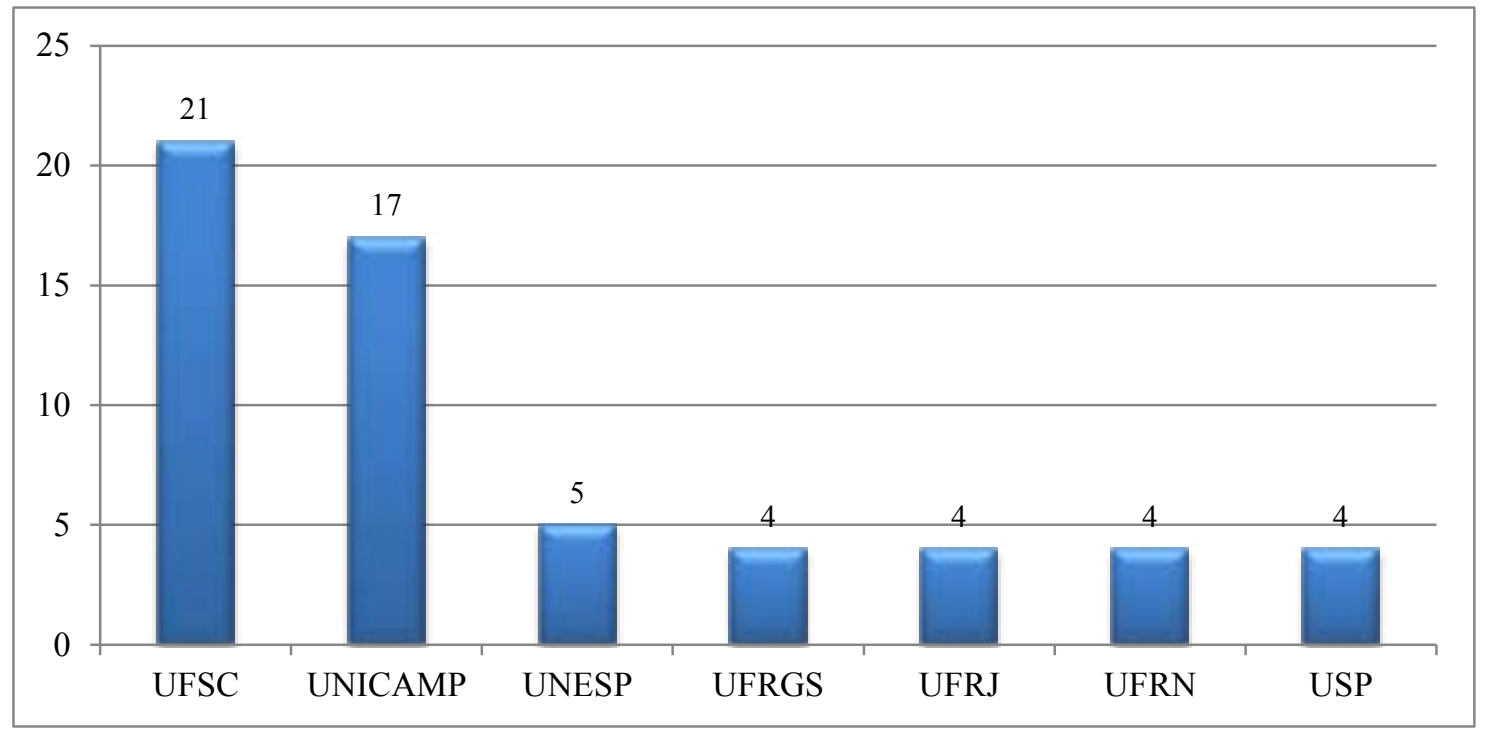

Gráfico 4 - Instituições 
Ainda em relação às instituições, vale destacar - como representado abaixo na tabela 01 - que dos 121 textos encontrados, 12 destes eram interinstitucionais. Ou seja, tratase de artigos produzidos por autores de universidades diferentes, artigos assinados por autores com vínculos institucionais distintos. Os outros 109 artigos correspondem a artigos institucionais, ou seja, publicações de autores vinculados a uma mesma instituição.

Tabela 1: Artigos Institucionais e Interinstitucionais

\begin{tabular}{|l|r|}
\hline Classificação & \multicolumn{2}{|c|}{ Quantidade } \\
\hline Interinstitucionais & 12 \\
\hline Institucionais & \\
\hline Total & \\
\hline \multicolumn{2}{|c|}{ Fonte: os autores } \\
\hline
\end{tabular}

A quantidade total de artigos por região foi de 125. Essa quantidade excedeu o total de artigos (121), devido a textos que eram interinstitucionais, como explicitado acima. No gráfico 6 , apresentamos o número de publicações por região. Podemos visualizar que a região com maior número de publicações foi a região Sudeste com um total de 53 publicações; seguida da região Sul com 38; depois a Nordeste com 11; o Centro-Oeste com 7; e, por fim o Norte com apenas 1 publicação. Podemos ver que todas 5 regiões oficiais do Brasil, possuem publicações a respeito da temática, com uma disparidade enorme da primeira para a última com uma diferença de 52 publicações.

É importante notar também que a RBCE recebe publicações de autores do exterior, assim foram encontradas 15 publicações internacionais tendo, portanto maior número de participação no periódico em relação as regiões Nordeste, Centro-Oeste e Norte (três das cinco regiões). 


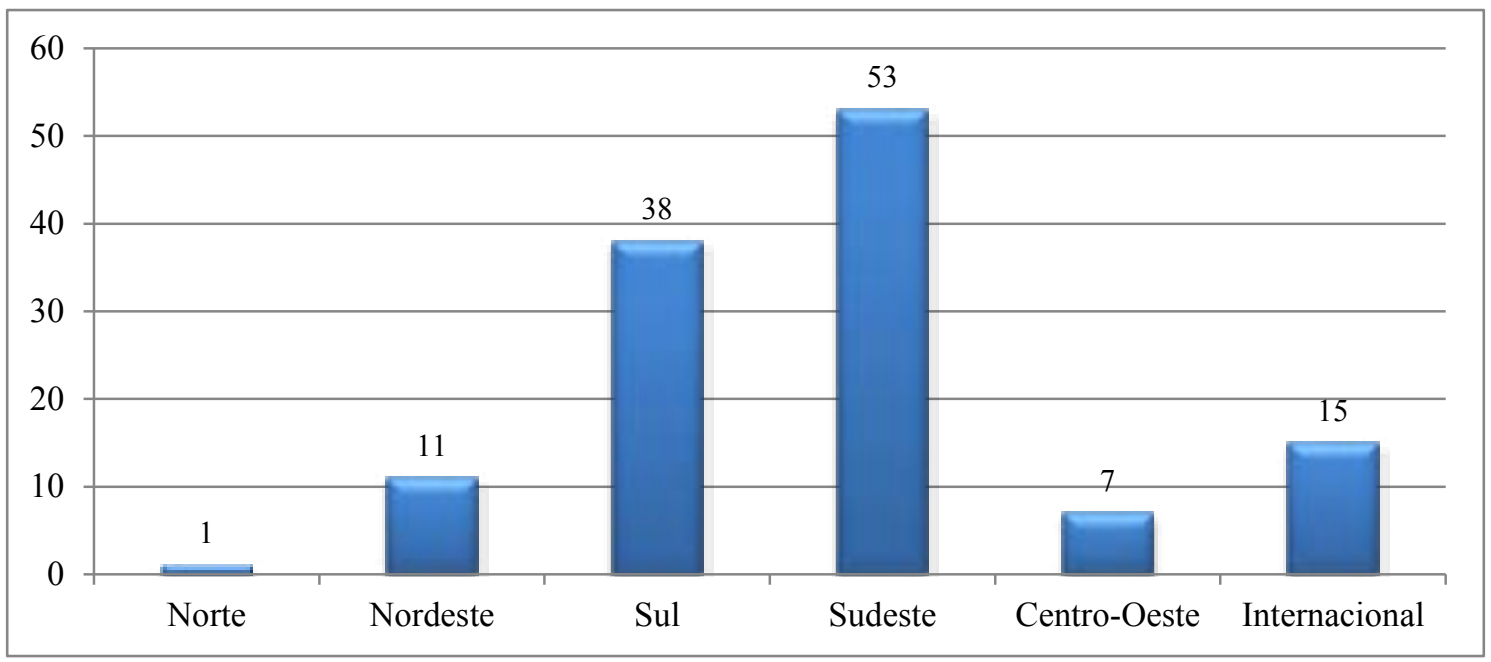

Gráfico 5 - Número de publicações por região

No gráfico 6 podemos visualizar a quantidade de publicação por titulação dos autores. Neste sentido, temos o seguinte quantitativo: doutores com 57 artigos; mestres com 31 publicações; mestrandos com 17; doutorandos com 15 artigos; graduados com 9 publicações; e, um empate entre graduandos e especialistas com 6 artigos cada. Vale aqui destacar que 37 publicações não informavam a titulação dos seus respectivos autores.

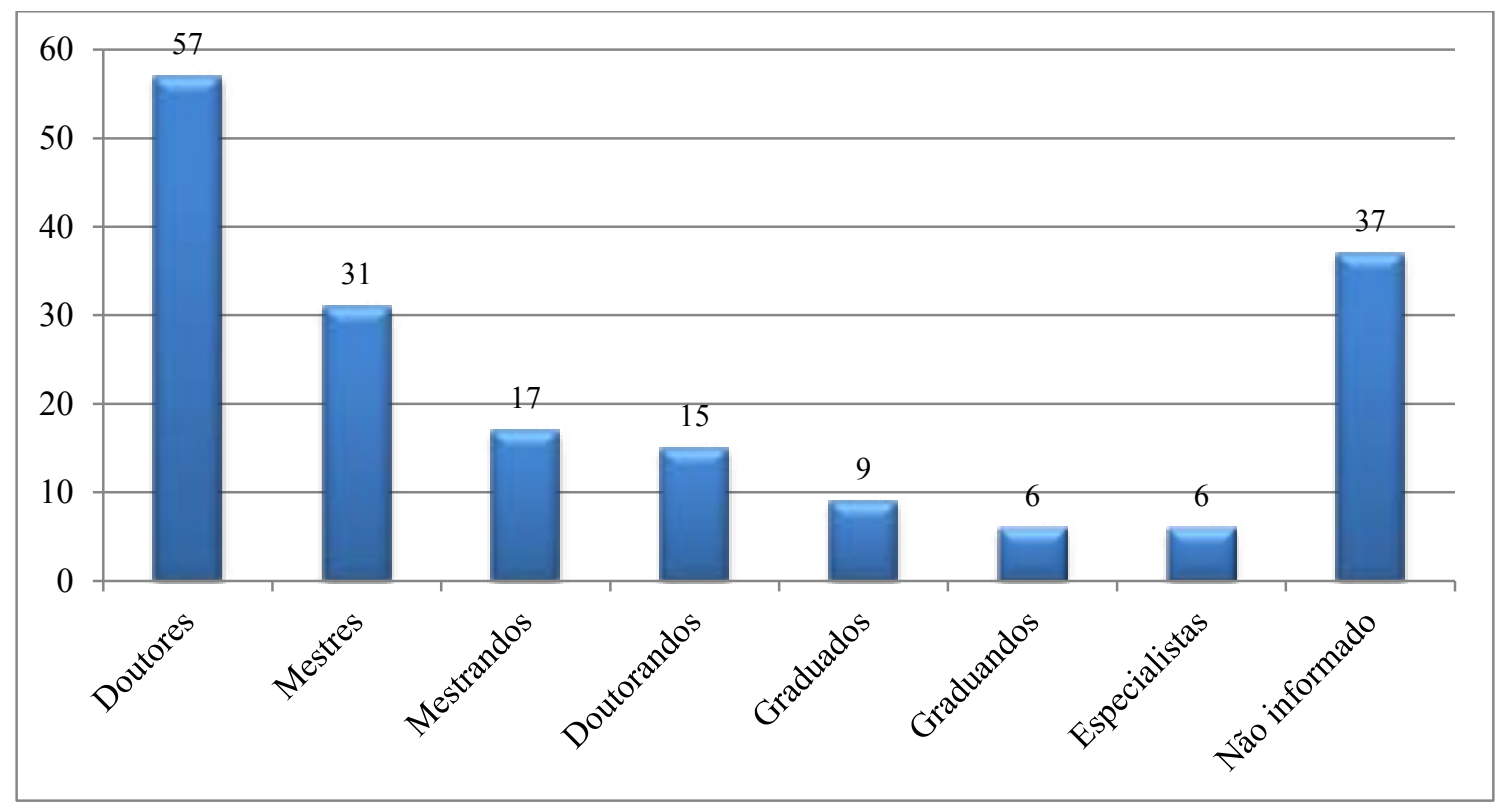

Gráfico 6 - Publicações por titulação

O gráfico 7 apresenta o quantitativo de autores que assinam o artigo. Dos 121 artigos, 
70 destes continham 1 autor; 29 tinham autoria de 2 autores; 13 contendo 3 autorias; 8 textos foram escritos por 4 autores diferentes; e, 1 artigo apareceu assinado por 11 autores. Neste sentido, podemos identificar que a maior parte dos artigos sobre o tema "corpo" veiculados na RBCE possuem apenas um autor.

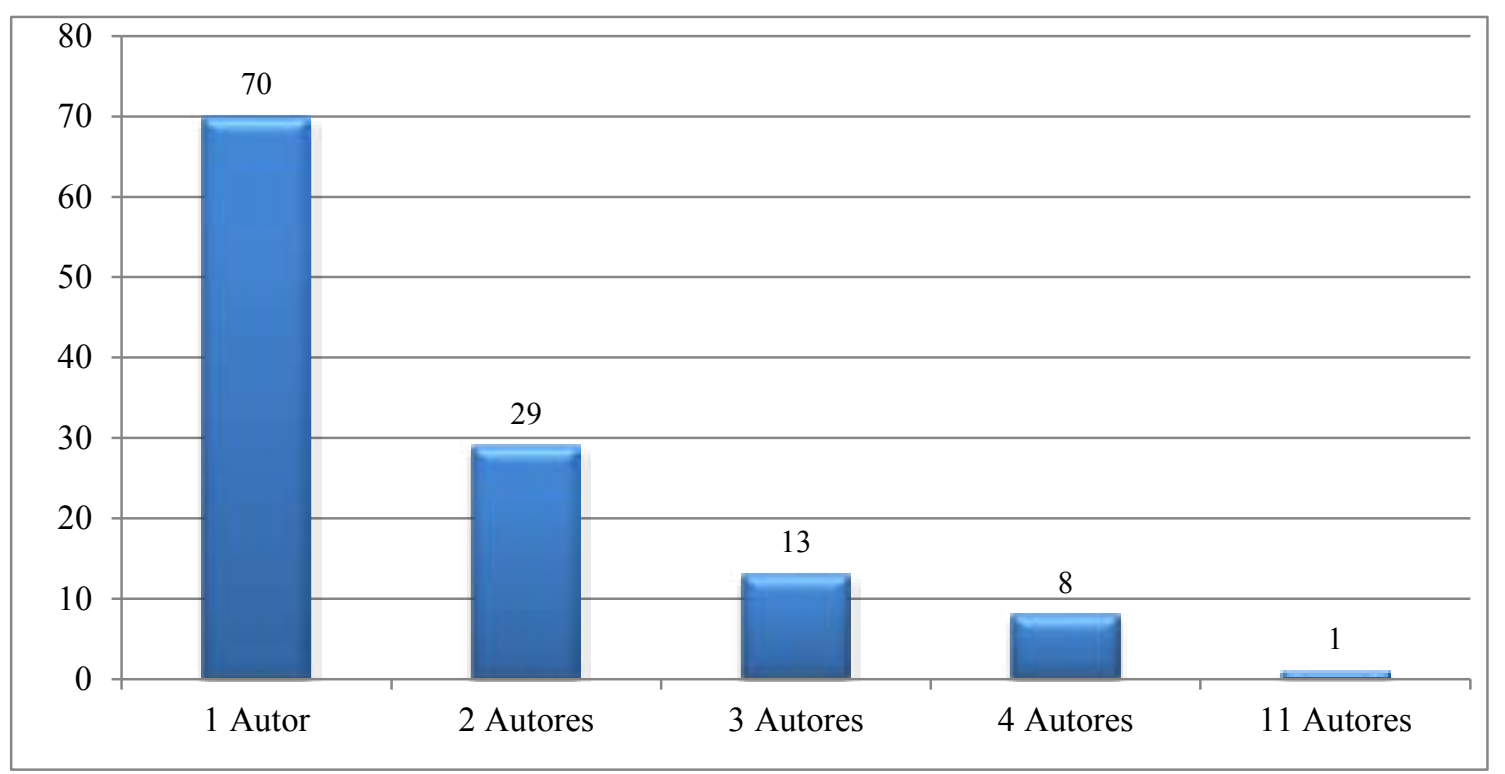

Gráfico 7 - Quantidade de autores por artigos

A partir da leitura dos textos e dos resumos dos mesmos os 121 artigos de nossa amostra foram divididos em categorias e subcategorias temáticas.

Como regra básica da estatística no que concerne à determinação de uma amostra retirada de uma população de dados, isto é, para quantificarmos objetos ou suas características, necessitamos antes definir discursivamente esses objetos segundo suas qualidades e características a fim de podermos, por exemplo, somar dois ou mais de uma mesma classe ou categoria; a fim de não formar conjuntos com base em coisas díspares. De acordo com Morais (2012, p. 173): "Para a Estatística, uma população é um conjunto de elementos com pelo menos uma característica em comum”. Por conseguinte, não é possível quantificar ou fazer cálculos com objetos distintos

Desse modo, toda quantificação depende das qualidades dos objetos, na medida em que essas é que permitem ao pesquisador agrupa-los em classes, conjuntos ou categorias e assim estabelecer relações (cf. VIEIRA, 2010, p. 11). Em suma, por esses 
motivos a análise que constituiu as bases deste trabalho está fundamentada em algumas categorias e subcategorias; sendo que essas foram formuladas a partir das atribuições que os pesquisadores aplicaram sobre o corpo humano; traçando um horizonte teóricometodológico que evidencia diferentes conceitos de corpo que não podem ser agrupados como objetos iguais ou idênticos. A tabela 2 apresenta estas categorias e subcategorias:

Tabela 2: Categorias e subcategorias temáticas

\begin{tabular}{|c|c|}
\hline Categorias & Subcategorias \\
\hline $\begin{array}{l}\text { 1) Fundamentos e propostas } \\
\text { pedagógicas }\end{array}$ & $\begin{array}{l}\text { 1.1 Propostas de ensino e de Metodologias } \\
\text { 1.2 Formação profissional } \\
\text { 1.3 Conteúdos } \\
\text { 1.4 Currículo }\end{array}$ \\
\hline 2) Educação Física e Epistemologia & $\begin{array}{l}\text { 2.1 Binômios } \\
\text { 2.2 Fundamentos de pensamento sobre } \\
\text { corpo e Educação Física } \\
\text { 2.3 Representação do corpo e da } \\
\text { Educação Física } \\
\text { 2.4 Episteme das Práticas Corporais } \\
\text { 2.5 Análise da produção do conhecimento }\end{array}$ \\
\hline 3) Corpo e Identidade Cultural & $\begin{array}{l}\text { 3.1 Gênero e sexualidade } \\
\text { 3.2 Grupos étnicos }\end{array}$ \\
\hline 4) Corpo e Estética & $\begin{array}{l}\text { 4.1 Sentir-se/ Eu } \\
\text { 4.2 Expectador/Outro }\end{array}$ \\
\hline
\end{tabular}

Fonte: os autores

Na categoria "Fundamentos e propostas pedagógicas" abarcamos os textos que dizem respeito a questões ligadas aos fundamentos e propostas pedagógicas na Educação Física, destinadas a compor o conjunto de paradigmas da docência na área. Ou seja, são textos em que o objetivo é propor subsídios para o professor e sua prática pedagógica, propondo reflexões acerca dos conhecimentos filosóficos, científicos e ideológicos, bem como aqueles chamados de tácitos, adquiridos durante sua docência. Tais conhecimentos são necessários para a formação do profissional de Educação Física, sendo sua intenção realizar seu trabalho pedagógico na escola ou não. Neste sentido, o conteúdo e objetivo dos textos aqui presentes, em seu âmago permeiam questões eminentemente pedagógicas que consideram desde propostas e metodologias de ensino, conteúdos trabalhados, bem 
como formação do profissional de Educação Física e o currículo que o "forma". Discutem problemas como os conflitos entre referenciais teórico-metodológicos tradicionais, críticos, reprodutivos, revolucionários, inovadores, democráticos e autoritários (SAVIANI, 2008; RAYS, 1991; TORRES, 1994).

A categoria "Educação Física e Epistemologia" engloba artigos que tratam das ciências que historicamente vem fundamentando a Educação Física em seus campos acadêmico, pedagógico e profissional. A epistemologia de um modo geral está interessada em duas perguntas: é possível conhecer a realidade (de um objeto)? Se é possível, quais as condições de conhecimento? Desta maneira, debate a problemática acerca do estatuto científico, em termos de um modelo teórico-metodológico do campo concernente à sua dependência e independência em relação a outras ciências como a filosofia, a antropologia, a sociologia, a pedagogia, dentre outras, no contexto das Ciências Humanas. Reflete sobre as diferenças entre tradição e epistemologia nas pesquisas do campo, tendo como pano de fundo as interações e rupturas entre senso comum e conhecimento científico. Pondera a respeito da produção de conhecimento em Educação Física analisando produções de teses, dissertações e periódicos do campo. Considera os dualismos, ou binômios como corpo/mente; natureza/cultura etc. como um dos principais fundamentos da racionalidade científica moderna e, sobretudo o campo da Educação Física.

Enquadram-se na categoria "Corpo e identidade cultural" os textos que possuem questões que giram em torno das problemáticas ligadas a identidade cultural. Qualquer que seja uma evidência de identidade, resulta por si só já uma definição de identidade. Quando identificamos o povo de um determinado país, usamos uma definição identitária operativa que é resultado de certo agenciamento da linguagem e, assim, não pode ser transportado, quanto ao ponto de vista de sua validade, para um plano, vamos assim dizer, ontológico (BÁRTOLO, 2007) ou natural como algo em si. Deste modo, são textos que abordam questões inerentes a grupos e seus códigos e símbolos que dão aos integrantes um sentido de pertencimento aquela determinada cultura, por meio de signos que em meio ao campo simbólico do grupo legitimam e marcam sua identidade. Ligado a isso, os textos destacam os debates relacionados a questão de gênero e sexualidade, tendo uma visão da temática oposta à dimensão puramente biológica do processo de diferenciação sexual trazendo 
para essa discussão aspectos culturais e políticos das relações entre sexos. Além disso, os textos também discutem questões relacionadas a demarcações identitárias de grupos como, por exemplo, por meio de uma mesma língua, de uma mesma cultura, genética etc. ou seja, questões de cunho étnico.

Na categoria "Corpo e estética" se enquadram os textos que possuem como objetivo estudar a experiência, ou seja, o "sentir". Do grego aisthetikós, derivado de aisthanesthai, estética nada mais é do que perceber e sentido (JAPIASSU e MARCONDES, 1996, p. 91). Sendo que, em termos filosóficos, o puro sentir deve se transmutar em uma investigação sobre as sensações corporais e seus atributos morais, políticos, sociais, culturais e econômicos; que para os gregos implicavam os fenômenos da alma. Segundo Japiassu e Marcondes (1996, p. 91), modernamente a estética, enquanto ciência, foi pensada por Baumgarten (XVIII) para designar todo e qualquer estudo da sensação, relativo à experiência, isto é, à empiria do gosto subjetivo: o que agrada ou satisfaz [ou não] aos sentidos. Apesar nome acima ter restringido a estética ao estudo do belo, Kant, ainda segundo Japiassu e Marcondes (1996, p. 91), generaliza o objeto de estudo para os princípios - ou aquilo que é condição determinante - de toda sensibilidade, seja o atributo belo ou feio. O juízo estético não é, portanto, lógico. Assim, um estudo estético não deseja saber o que um sujeito ou um grupo compreende acerca de um fenômeno, mas, como esse é sentido e gera emoções, em detrimento de qualquer expressão linguística metódica e rigorosa. Ou seja, embora um estudo estético dependa da linguagem falada ou escrita, já que os seres humanos assim se expressam, essa não obedece as regras, o rigor ou os fluxos da razão; mas sim o da fruição, mais livre, dos sentidos e dos sentimentos passíveis de serem transformados, ou metaforizados, em palavras segundo alguma sintaxe. É necessário considerar que embora na maior parte dos casos de nossa pesquisa os trabalhos não apresentem qualquer noção ou concepção estética acerca do corpo, os referidos estudos assim podem se enquadrados, como estéticos, justamente porque têm como objeto as sensações corpóreas, de sujeitos ou grupos humanos, responsáveis por gerar algum juízo estético nas pessoas investigadas, tanto em relação a si mesmas quanto aos outros. Assim, o "sentir" aqui está ligado tanto a uma percepção do outro (expectador/outro), ou seja, as significações e representações que um determinado fenômeno produz naquele que está "de fora assistindo". Está ligado 
também ao "sentir-se", ou na percepção que um sujeito tem ao fazer parte de um grupo, ao praticar um esporte, uma dança, ao ouvir uma música, ao ver um quadro etc.

A tabela 3 mostra a quantificação das categorias e subcategorias nas quais os textos de nossa pesquisa foram divididos e subdivididos. A categoria que abarcou mais textos foi a "Educação Física e Epistemologia", com 75 produções, subdivididas nas subcategorias: "binômios" (6); "fundamentos do pensamento sobre corpo e Educação Física" (36); "representação do corpo e da Educação Física" (14); "episteme das práticas corporais" (15) e "análise da produção do conhecimento" (4). A categoria "Fundamentos e proposta pedagógica" teve um total de 22 textos com as subcategorias: "proposta de ensino e de metodologias" (16); "formação profissional" (2); "conteúdos" (3) e "currículo" (1). Já a categoria "Corpo e estética", englobou 14 produções, subdivididas por: "Sentir-se/eu" (9) e "expectador/outro" (5). Por fim, a categoria "Corpo e identidade cultural", foi a que menos abarcou textos, um total de 10 . Os textos desta categorias foram subdivididos nas seguintes subcategorias: "gênero e sexualidade" (2) e "grupos étnicos" (8). 
Tabela 3: Quantificação das categorias e subcategorias temáticas

\begin{tabular}{|c|c|c|c|}
\hline Categorias & $\begin{array}{l}\text { Total de artigos } \\
\text { por categoria }\end{array}$ & Subcategorias & $\begin{array}{l}\text { Total de artigos por } \\
\text { subcategorias }\end{array}$ \\
\hline \multirow{4}{*}{$\begin{array}{l}\text { Fundamentos e } \\
\text { proposta } \\
\text { pedagógica }\end{array}$} & \multirow{4}{*}{22} & $\begin{array}{l}\text { Propostas de ensino e de } \\
\text { Metodologias }\end{array}$ & 16 \\
\hline & & Formação profissional & 2 \\
\hline & & Conteúdos & 3 \\
\hline & & Currículo & 1 \\
\hline \multirow{5}{*}{$\begin{array}{l}\text { Educação Física } \\
\text { Epistemologia }\end{array}$} & \multirow[t]{5}{*}{75} & Binômios & 6 \\
\hline & & $\begin{array}{l}\text { Fundamentos de } \\
\text { pensamento sobre corpo e } \\
\text { Educação Física }\end{array}$ & 36 \\
\hline & & $\begin{array}{l}\text { Representação do corpo e } \\
\text { da Educação Física }\end{array}$ & 14 \\
\hline & & $\begin{array}{l}\text { Episteme das Práticas } \\
\text { Corporais }\end{array}$ & 15 \\
\hline & & $\begin{array}{l}\text { Análise da produção do } \\
\text { conhecimento }\end{array}$ & 4 \\
\hline \multirow{2}{*}{$\begin{array}{l}\text { Corpo e } \\
\text { identidade } \\
\text { cultural }\end{array}$} & \multirow[t]{2}{*}{10} & Gênero e sexualidade & 2 \\
\hline & & Grupos étnicos & 8 \\
\hline \multirow[t]{2}{*}{ Corpo e estética } & \multirow[t]{2}{*}{14} & Sentir-se/eu & 9 \\
\hline & & Expectador/outro & 5 \\
\hline
\end{tabular}

Fonte: os autores 


\section{CONSIDERAÇÕES FINAIS}

Retomando o objetivo do presente artigo que foi o de realizar um levantamento da produção do conhecimento da temática "corpo" na Revista Brasileira de Ciências do Esporte no período de 1979-2012 percebemos ao quantificar e descrever os dados que inúmeros questionamentos em volta da temática emergem a partir dos dados apresentados podendo contribuir bastante para futuros estudos relacionados ao "corpo" na EF.

Como já descrito, a coleta e organização dos dados foi organizada a partir da busca no site da revista marcando as opções por título e resumo, a partir das seguintes palavraschave: "corpo", "corporeidade", "corporalidade" e "corporal". O resultado desta busca totalizou 172 artigos. Aplicados alguns critérios de corte foram excluídos do estudo 51 artigos e a nossa amostra ficou então composta por 121 artigos publicados no período entre 1986 a 2012.

Com a amostra definida buscou-se dados bibliométricos relativos às publicações que sintetizaram informações relativas a ano de publicação e informações sobre os autores (quantidade, região, titulação, sexo), bem como sobre a temática geral do texto (resumo, título, mês e ano de publicação). Desta forma nos preocupamos em identificar as seguintes informações dos textos: Título; Resumo; Tema Central; Mês/Ano/Edição; Instituição; Região; Titulação dos Autores; Número de Autores. Estes dados apontaram vislumbres interessantes no sentido de perceber como está sendo a produção do conhecimento a respeito da temática corpo na EF.

Além disso, na descrição do quantitativo das temáticas feita a partir da leitura dor artigos e seus respectivos resumos feita categorias e subcategorias a fim de identificarmos as principais temáticas ligadas ao estudo do corpo no âmbito da EF. Desta forma foram identificadas 4 categorias: 1) "Fundamentos e propostas pedagógicas", constituída pelas subcategorias: Propostas de ensino e de Metodologias; Formação profissional; Conteúdos; e, Currículo. 2) "Educação Física e Epistemologia" constituída pelas subcategorias Binômios; Fundamentos de pensamento sobre corpo e Educação Física; Representação do corpo e da Educação Física; Episteme das Práticas Corporais; e, Análise da produção do conhecimento. 3) "Corpo e identidade cultural” constituída pelas subcategorias Gênero e sexualidade; e, Grupos étnicos. 4) "Corpo e estética" constituída pelas subcategorias 
Sentir-se/ Eu; e, Expectador/Outro.

Ao quantificar as aparições dessas categorias na pesquisa, trazemos a "Educação Física e Epistemologia" com maior número de aparições (75), seguidas de "Fundamentos e propostas pedagógicas" (22), "Corpo e estética" (14) e "Corpo e identidade cultural" (10) respectivamente. 


\section{REFERÊNCIAS}

BÁRTOLO, J. Corpo e Sentido: estudos intersemióticos. Livros LabCom: Covilã: Portugal, 2007.

BRACHT, V. et al. A Educação Física Escolar como tema da produção do conhecimento nos periódicos da área no Brasil (1980-2010): parte I. Movimento: Porto Alegre, v. 17, n. 02, p. 11-34, abr/jun, 2011.

BUFREM, L.; PRATES, Y. O saber científico registrado e as práticas de mensuração da informação. Ci. Inf., Brasília, v.34, n.2, p. 9-25, maio-ago, 2005.

JAPIASSU, H; MARCONDES, D. Dicionário básico de filosofia. 3a ed. Rio de Janeiro: Jorge Zahar Ed., 1996.

LE BRETON, D. A sociologia do corpo. Tradução de Sonia M. S. Fuhrmann. 3d. Petrópolis/RJ: Vozes, 2009.

MORAIS, P. R. de. Método estatístico. In: HEGENBERG, L. et al. (orgs.). Métodos de pesquisa: de Sócrates a Marx e Popper. São Paulo: Atlas, 2012.

NÓBREGA. T. P. Corpo e Epistemologia. In NÓBREGA. T. P. (ORG.) Epistemologia, saberes e práticas da Educação Física. João Pessoa: Editora Universitária / UFPB, p. 59-74. 2006.

NORONHA, D, P.; FERREIRA, S. M. S. P. Revisões de literatura. In: CAMPELLO, B. S.; CONDÓN, B, V.; KREMER, J. M (orgs). Fontes de informações para pesquisadores e profissionais. Belo Horizonte: UFMG, 2000. 
PEREIRA, J. C. R. Análise de Dados Qualitativos: estratégias metodológicas para as Ciências da Saúde, Humanas e Sociais. 3a ed. São Paulo: Editora da Universidade de São Paulo, 2004.

RAYS, O. A. A questão da metodologia do ensino na didática escolar. In: VEIGA, I. P. A. (org.). Repensando a didática. 5a ed. Campinas, SP: Papirus, 1991 p. 83-95.

SAVIANI, D. Escola e democracia. Campinas, SP: Autores Associados, 2008. (Coleção educação contemporânea).

TORRES, R. M. Que (e como) é necessário aprender? necessidades básicas de aprendizagem e conteúdos curriculares. Tradução de Tália Bugel. Campinas, SP: Papirus, 1994. (Educação Internacional do Instituto Paulo Freire).

VIEIRA, S. O que é estatística? 2a ed. São Paulo: Brasiliense, 2010. (Coleção Primeiros Passos; 195) 


\section{THE "BODY" AS A TOPIC OF KNOWLEDGE PRODUCTION IN THE BRAZILIAN JOURNAL OF SPORT SCIENCES - RBCE (1979-2012)}

Abstract: Bibliometry of the knowledge production surrounding the topic "body" in the Brazilian Journal of Sport Science from 1979 to 2012. This is a bibliometric study with a qualitative and quantitative approach which is characterized as descriptive. The search was based on the following terms: "body", "corporeity", "corporal" and "corporeality", all of them applied according to the following filters: "title" and "abstract". The results found 121 paper works from which measures scales were built to fit the quantitative of the scientific productions. The studies which were analyzed were grouped into six categories: "foundations and pedagogic proposals", "Physical Education and epistemology", "body and cultural identity", "body and aesthetics", "motivation and exercise" and "others."

Key words: Bibliometrics; Body; Brazilian Journal of Sports Sciences; Physical Education.

\section{EL “CUERPO” COMO TEMA DE LA PRODUCCIÓN DEL CONOCIMIENTO EN LA REVISTA BRASILEÑA CIENCIAS DEL DEPORTE - RBCE (1979- 2012)}

Resumen: Bibliometría de la producción del conocimiento de la temática "cuerpo" en la Revista Brasileira de Ciências do Esporte 1979-2012. El estudio es del tipo bibliométrico con una abordagem qualiquantitativa de carácter descriptivo. Los términos de búsqueda fueron: "cuerpo”, "corporeidad”, ““ccorporal” y "corporalidad”, todos aplicados considerando el "título" y el "resumen". Como resultado fueron encontrados 121 trabajos apartir de los cuales fueron construidas escalas de medidas para encuadrar lo cuantitativo de las producciones científicas. Los trabajos analizados fueron agrupados en seis categorías: "fundamentos y propuestas pedagógicas", "Educación Física y epistemología”, "cuerpo y identidad cultural”, "cuerpo y estética", "motivación y ejercicio" y "otros".

Palavras chave: Bibliometría; Cuerpo; Revista Brasileira de Ciências do Esporte; Educación Física 